
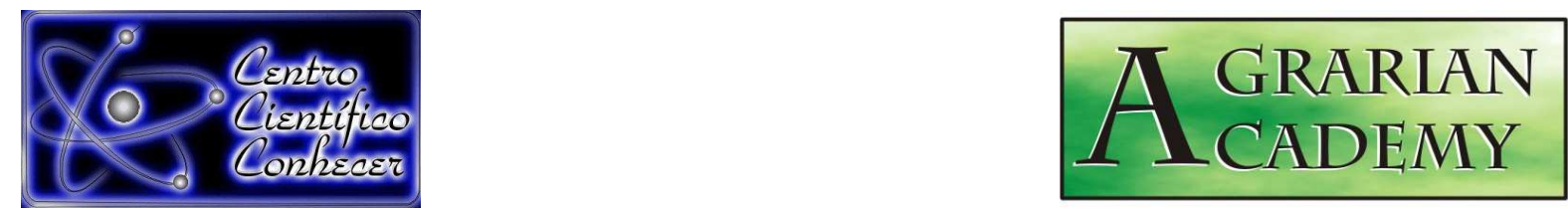

\title{
ATRIBUTOS QUÍMICOS E FÍSICOS DO SOLO SOB DIFERENTES MANEJOS NA MICRORREGIÃO SERRANA DOS QUILOMBOS - ALAGOAS
}

José Thales Pantaleão Ferreira ${ }^{1}$; Elvis Pantaleão Ferreira ${ }^{2}$; Wellington Costa da Silva $^{3}$, Igor Tenório Marinho da Rocha ${ }^{4}$

${ }^{1}$ Engenheiro Agrônomo, Doutorando em Agronomia: Solos e Nutrição de Plantas na Universidade Federal do Ceará. E-mail: agronomia_thales@hotmail.com

${ }^{2}$ Técnico em Agricultura do Departamento de Solos, Instituto Federal do Espírito Santo - IFES, Campus Santa Teresa.

${ }^{3}$ Engenheiro Agrônomo, Doutorando em Proteção de Plantas na Universidade Federal de Alagoas.

${ }^{4}$ Engenheiro Agrônomo, Doutorando Ciência do Solo na Universidade Federal Rural de Pernambuco.

Recebido em: 03/01/2014 - Aprovado em: 04/04/2014 - Publicado em: 12/04/2014

\section{RESUMO}

O uso agrícola altera os atributos do solo. Visando analisar as modificações químicas e físicas do solo decorrentes de seu uso, objetivou-se avaliar atributos químicos e físicos do solo submetido ao plantio de laranja e pastagem em comparação com o seu estado natural (mata). Para cada uso foram coletadas amostras nas profundidades de $0-20 \mathrm{~cm}$, procedendo as análises químicas e físicas do solo. O uso do solo com pastagem, cultivo de laranja e mata nativa não diferiram estatisticamente entre si em todas as variáveis analisadas, possivelmente em função do pouco tempo de conversão da área de pastagem para cultivo de laranja. $O$ dendrograma de similaridade construído com as variáveis dos atributos químicos e físicos do solo mostra que a pastagem e mata nativa são mais semelhantes entre si, estando em grupo distinto do cultivo com laranja.

PALAVRAS - CHAVE: Iaranja lima, manejo do solo, mata nativa, pastagem

\section{CHEMICAL AND PHYSICAL SOIL PROPERTIES WITH DIFFERENT MANAGEMENTS IN THE MOUNTAINOUS MICRO-REGION OF QUILOMBOS - ALAGOAS}

\begin{abstract}
The agricultural land use changes the attributes of the soil. To analyze the chemical changes of soil resulting from its use, aimed to evaluate some chemical and physical soil properties when subjected to plant orange, pasture and its relationship to its natural state (forest). For each use samples were collected at depths of $0-20 \mathrm{~cm}$, carrying the chemical and physical soil analysis. The land use to grazing, cultivation of orange and bushland not differ statistically in all variables, possibly due to the short time of conversion of pasture area for growing oranges. The similarity dendrogram constructed with the variables of chemical and physical soil properties shows that pasture and native forest are more similar to each other, being in a different group with orange cultivation.
\end{abstract}

KEYWORDS: orange lime, grassland, bushland 


\section{INTRODUÇÃO}

O uso agrícola das terras altera as propriedades do solo, dependendo das condições edáficas e climáticas. Dessa forma, diferentes sistemas de manejo resultam em mudanças na composição e arranjo dos constituintes do solo, que podem em alguns casos, prejudicar a conservação desse recurso natural e reduzir a produtividade das culturas (REINERT, 1998). De acordo com SILVA \& MIELNICZUK (1997), a utilização intensiva da terra, com sistemas de cultivos inadequados, tem contribuído para a degradação das características físicas, químicas e biológicas do solo. É comum observar na literatura relatos de modificações físicas do solo pelo uso de maquinários agrícolas (MARASCA et al., 2013) e pela utilização excessiva de sistemas de irrigação causando, principalmente, a salinização (LEITE et al., 2007; VYSHPOLSKY et al., 2008).

Segundo LOGAN (1990), o solo é um organismo vivo, e como tal possui um complexo sistema de auto-regulação, que controla, em última análise, o suprimento de nutrientes, a capacidade tampão de $\mathrm{pH}$, a decomposição da matéria orgânica, assim como a degradação ou inativação de compostos orgânicos tóxicos, metais tóxicos e a incidência de patógenos. Estes atributos, no entanto, são bem expressos num solo "saudável", mas suas capacidades são finitas, e podem ser sobrecarregadas por um manejo inadequado.

A compreensão e a quantificação dos impactos dos diferentes sistemas de manejo nas propriedades físicas, químicas e biológicas do solo, são de fundamentais importâncias para a conservação desse recurso natural, uma vez que, essas alterações decorrentes desses sistemas, normalmente são comparadas ao solo original desenvolvido sob floresta, a qual em muitas vezes, com a retirada da cobertura vegetal original e a implantação de culturas, aliadas a práticas de manejo inadequadas, promovem o rompimento do equilíbrio entre o solo e o meio, modificando suas propriedades químicas, físicas e biológicas, limitando sua utilização agrícola e tornando-o mais suscetível à erosão. Neste sentido, o monitoramento da qualidade química e física do solo de forma que possam ser sugeridas modificações nos sistemas de manejo em utilização pelos agricultores a tempo de evitar a sua degradação, é necessário afim de definir atributos do solo e do ambiente sensíveis ao manejo e de fácil determinação (MIELNICZUK, 1999). Algumas características físicas como o intervalo hídrico ótimo $(\mathrm{IHO})$ e o índice $\mathrm{S}$ já foram utilizados com sucesso para diferenciar o potencial de suporte à mecanização de solos com texturas diferentes (CAVALIERI et al., 2011).

O presente estudo teve como objetivo, avaliar as mudanças em alguns atributos químicos e físicos do solo quando submetido ao plantio de laranja, pastagem e a relação com o seu estado natural (mata).

\section{MATERIAL E MÉTODOS}

As áreas selecionadas para estudo situam-se no município de Santana do Mundaú, localizado na Microrregião Serrana dos Quilombos do Estado de Alagoas, mais precisamente na região do Vale do Mundaú (Figura 1). A cidade possui relevo bastante acidentado, formados principalmente por solos distróficos classificados como Argissolos e em menor expressão se encontram os Latossolos e Gleissolos (EMBRAPA, 2006). O município apresenta precipitação na ordem de $1.600 \mathrm{~mm}$ anuais, tendo início em fevereiro e término em outubro (CPRM, 2005). 


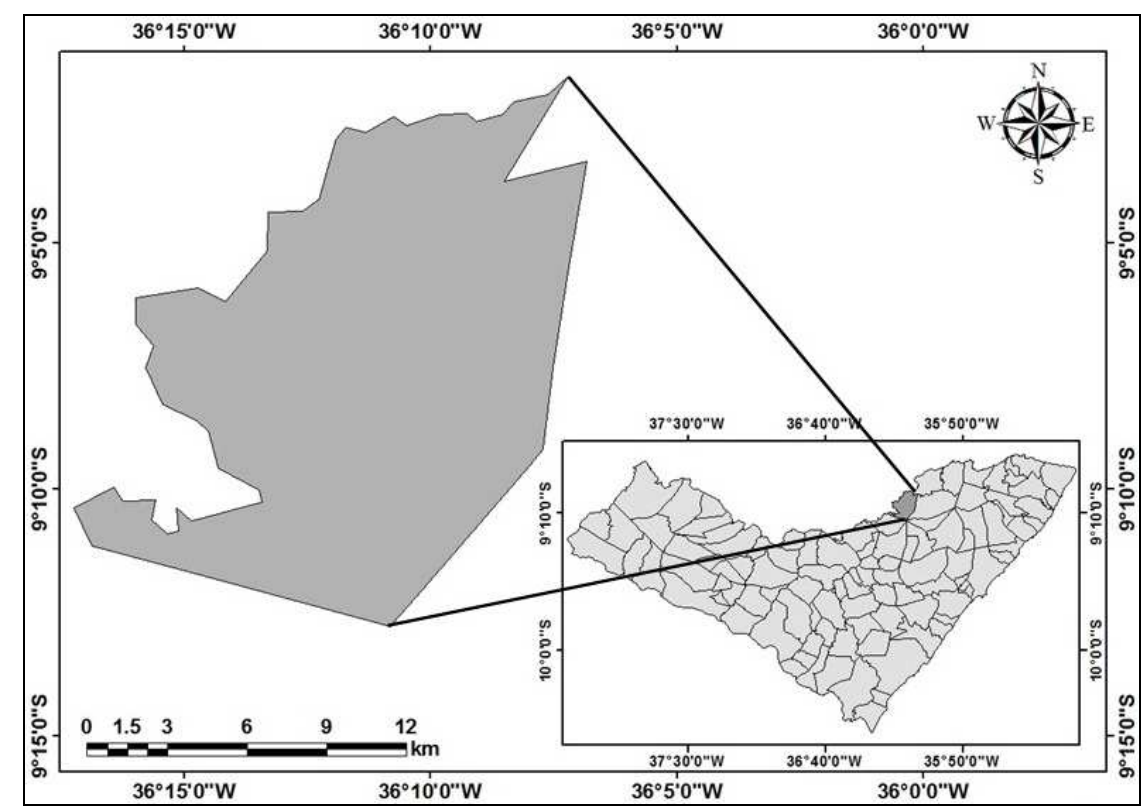

FIGURA 1. Localização do município de Santana do Mundaú no estado de Alagoas.

Foram selecionadas três áreas (laranja, pastagem e mata) próximas, com mesmas condições topográficas e edafoclimáticas para coleta de solo. A área de pastagem possui mais de 20 anos de uso e a área de laranja possui seis anos de cultivo, a qual anteriormente era utilizada como pastagem. Ambas as condições não realizam qualquer utilização de adubos químicos, orgânicos e práticas de calagem.

Em cada área estudada, foram separadas glebas homogêneas e realizada as coletas de amostras de solos segundo as recomendações da EMBRAPA (1997). Em cada local de estudo, realizou-se a coleta de 10 amostras simples, na profundidade de $0-20 \mathrm{~cm}$. Após as coletas, as amostras compostas foram encaminhadas ao laboratório, secas ao ar, destorroadas, passadas em peneira com malha de $2 \mathrm{~mm}$ de abertura e procedidas as análises químicas ( $\mathrm{pH}$ em água, $\mathrm{Ca}, \mathrm{Mg}, \mathrm{K}, \mathrm{Na}, \mathrm{Al}, \mathrm{H}+\mathrm{Al}$, CO) e físicas (densidade de partícula, densidade do solo, porosidade total), conforme recomendações da EMBRAPA (1997).

A partir dos dados das análises químicas foram obtidos os seguintes valores: $\mathrm{SB}$ (Soma das bases) $=\mathrm{K}^{+}+\mathrm{Mg}^{+2}+\mathrm{Ca}^{+2}+\mathrm{Na}^{+}$; CTCefet. (Capacidade de troca catiônica efetiva) $=\mathrm{SB}+\mathrm{Al}^{+3}$; CTCpot. (Capacidade de troca catiônica potencial) $=$ $\mathrm{SB}+(\mathrm{H}+\mathrm{Al}) ; \mathrm{V}$ (Saturação por bases) = SB / CTCefet.; $m$ (Saturação por Alumínio) $=\left(\mathrm{Al}^{+3} /\right.$ CTCefet. $) \times 100 ;$ C.O = Carbono Orgânico; M.O = 1,724 x C. O.

Os dados das análises químicas foram analisados estatisticamente pelo teste de Tukey ao nível de 5\% de significância, por meio do programa Assistat.

Foi realizada uma análise de agrupamento (cluster analysis) no software Statistica 7 para os atributos químicos ( $\mathrm{pH}$ água, $\mathrm{Ca}^{2+}, \mathrm{Mg}^{2+}, \mathrm{Na}^{+}, \mathrm{K}^{+}, \mathrm{Al}^{3+}, \mathrm{H}+\mathrm{Al}$, Valor S, m\%, CTCefet., CTCpot., CO e P) e físicos (densidade de partícula, densidade do solo, porosidade total), construindo dendrogramas de similaridade, mensurando a distância euclidiana e utilizando o modo de ligação completa com dados padronizados.

\section{RESULTADOS E DISCUSSÃO}

A acidez ativa e o teor de alumínio trocável nas três condições de uso do solo, não diferiram estatisticamente entre si. A acidez ativa do solo variou de 4,1 a 4,2 
sendo considerada muito elevada (gráfico) e o alumínio trocável variou de 1,1 a 1,4 $\mathrm{cmol}_{\mathrm{c}} \mathrm{kg}^{-1}$, sendo mais elevado na condição de pastagem e considerado elevado, conforme critérios de RIBEIRO et al., (1999).

O baixo $\mathrm{pH}$ da solução do solo e elevados teores de alumínio trocável está diretamente relacionado com a gênese do solo, mineralogia e condição de fertilidade, podendo ocasionar baixas produtividades agrícolas, redução no desenvolvimento radicular e limitação na absorção de nutrientes e água. Sendo assim, a análise das três condições de uso do solo (gráfico 1), mostra a necessidade de correção do solo com a utilização de calagem, elevando o pH do solo, diminuindo ou anulando os efeitos tóxicos do alumínio e elevando os teores de cálcio e magnésio do solo (SOUSA et al., 2007).

Segundo HORST et al. (2010) o alumínio na solução do solo nas formas monoméricas inorgânicas, particularmente como $\mathrm{Al}^{3+}$, é considerado fitotóxico, reduzindo o alongamento celular, o que impede o crescimento radicular (SOUZA et al., 2006) e consequentemente o desenvolvimento das plantas.

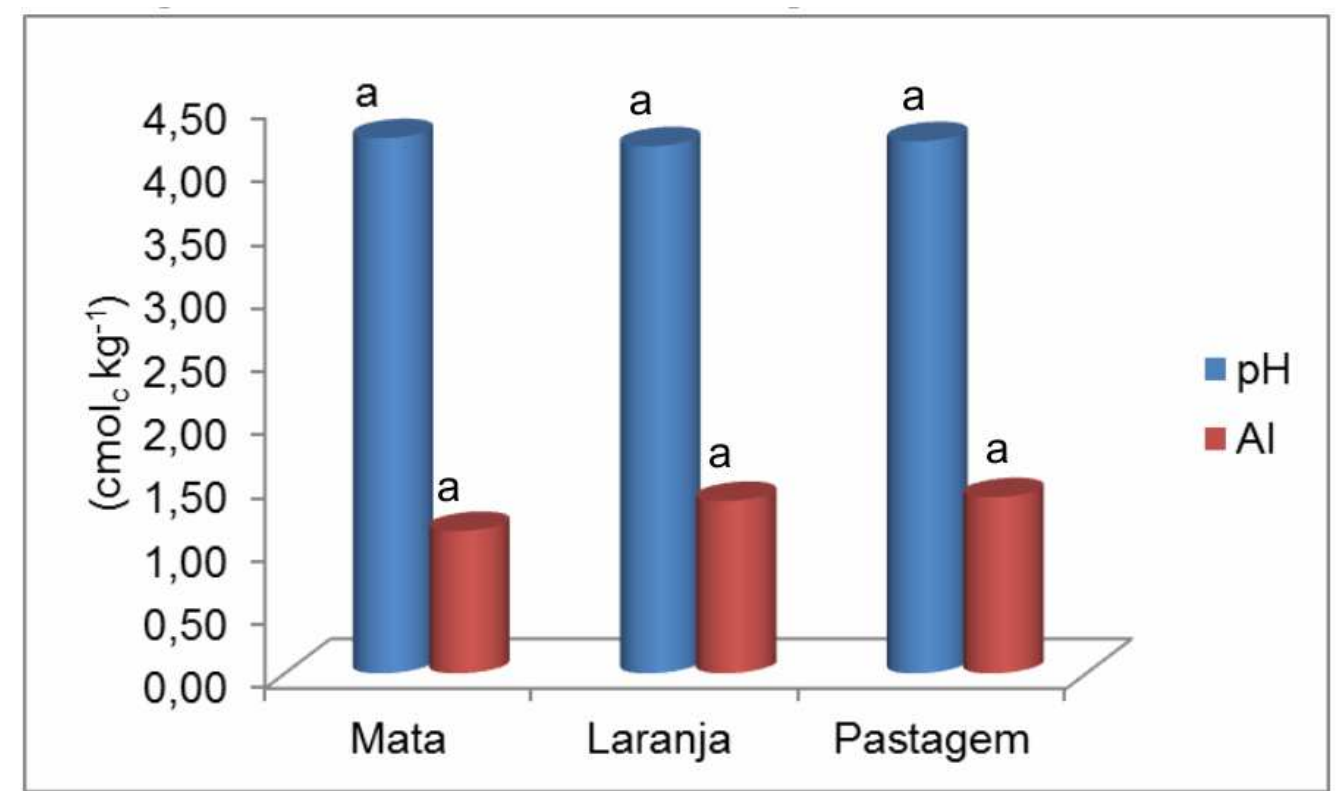

GRÁFICO 1. Acidez ativa do solo $(\mathrm{pH})$ e alumínio trocável nas três condições de uso do solo estudadas. Médias seguidas de mesma letra não diferem estatisticamente entre si pelo teste de Tukey ao nível de $5 \%$ de probabilidade.

Os teores de cálcio (gráfico 2 ) nas três situações estudadas foram estatisticamente semelhantes, porém o teor $\left(1,52 \mathrm{cmol}_{\mathrm{c}} \mathrm{kg}^{-1}\right)$ na condição de cultivo com laranja foi ligeiramente maior e considerado médio conforme critérios de RIBEIRO et al. (1999). Na mata e pastagem os teores foram considerados baixos, sendo respectivamente 0,89 e $0,63 \mathrm{cmol}_{\mathrm{c}} \mathrm{kg}^{-1}$.

$\mathrm{O}$ solo da pastagem estudada necessita urgentemente de calagem para corrigir os níveis baixos de cálcio no solo e o cultivo de laranja deve ser monitorado para correção assim que os níveis de cálcio baixar, pois o cálcio está presente na membrana citoplasmática e nas paredes celulares das células das plantas, possuindo importante papel no crescimento das raízes e dos meristemas; na germinação do grão de pólen e crescimento do tubo polínico; na nodulação de leguminosas e na ativação de um grande número de enzimas que regulam o 
crescimento das plantas. A falta de cálcio afeta principalmente os pontos de crescimento radicular, paralisando o crescimento, podendo haver morte de raízes (MALAVOLTA, 1996a; VITTI et al., 2006).

Os teores de magnésio dos solos estudados (gráfico 2) foram considerados muito alto, variando de $2,16 \mathrm{cmol}_{\mathrm{c}} \mathrm{kg}^{-1}$ na condição de mata e $1,81 \mathrm{cmol}_{\mathrm{c}} \mathrm{kg}^{-1} \mathrm{na}$ condição de pastagem. Desta forma, observa-se que para esta situação o melhor seria uma calagem com calcário calcítico $\left(\mathrm{CaCO}_{3}\right)$ para elevar os teores de cálcio no solo evitar um desbalanceamento nos teores de cálcio e magnésio no solo, além de corrigir o pH do solo e controlar os efeitos tóxicos do alumínio que encontra-se elevado.

Não é comum encontrar solos com teores de magnésio mais elevados que o de cálcio, como observado neste estudo. Isto se deve ao fato dos materiais de origem dos solos geralmente terem mais cálcio que magnésio, além do magnésio não ser adsorvido tão fortemente quanto o cálcio pelas argilas e matéria orgânica, estando mais predisposto a sofrer lixiviação (VITTI et al., 2006). Portanto, possivelmente o material de origem destes solos são ricos em minerais que possuem elevada quantidade de magnésio em sua estrutura.

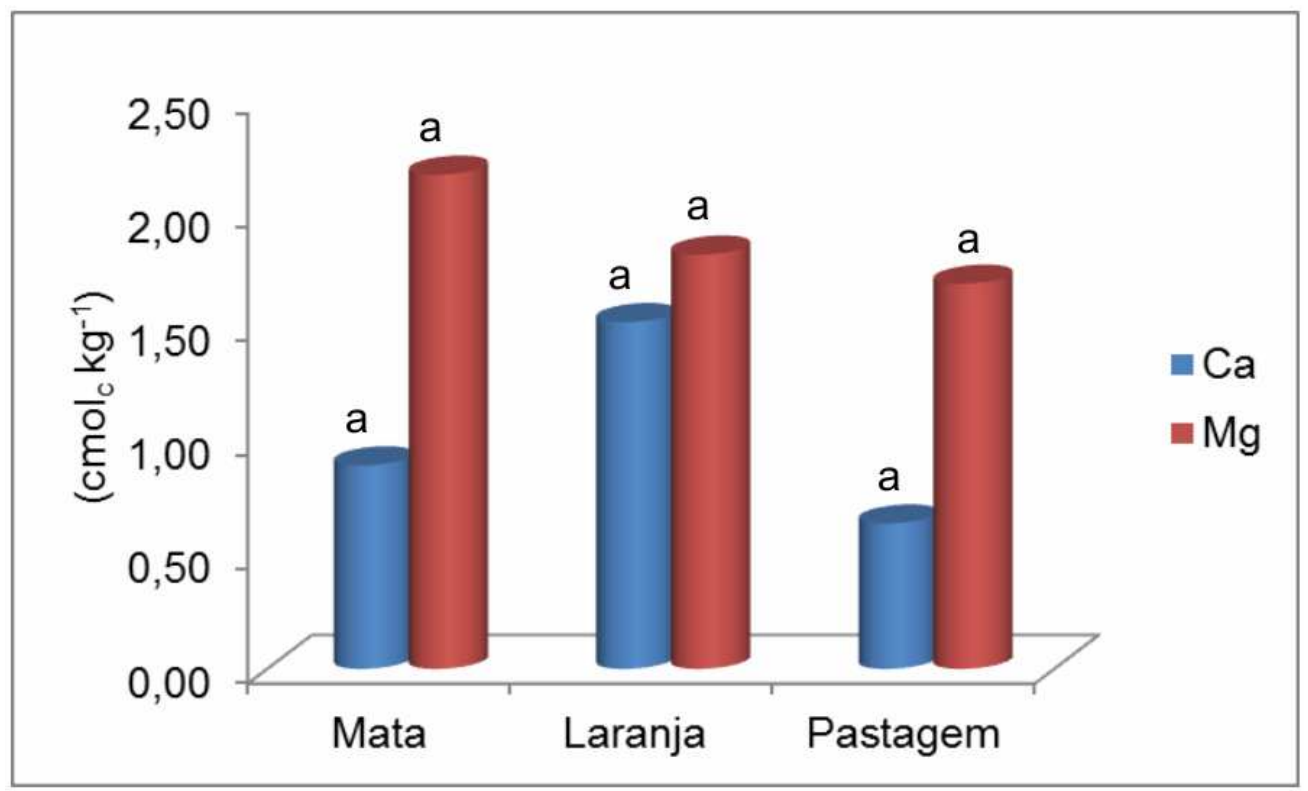

GRÁFICO 2. Teores de cálcio e magnésio nas três condições de uso do solo estudadas. Médias seguidas de mesma letra não diferem estatisticamente entre si pelo teste de Tukey ao nível de 5\% de probabilidade.

O magnésio é essencial no processo de fotossíntese das plantas, sendo componente importante das clorofilas. Além de ser um ativador enzimático essencial no processo de transferência de energia no processo de fotossíntese e no metabolismo do nitrogênio, afetando a síntese de proteínas nas plantas (MALAVOLTA, 1996b; VITTI et al., 2006). Desta forma, sua deficiência pode trazer sérios prejuízos a produção agrícola em geral.

Os teores de potássio são considerados muito elevados, variando de 0,49 $\mathrm{cmol}_{\mathrm{c}} \mathrm{kg}^{-1}$ na condição de pastagem e $0,34 \mathrm{cmol}_{\mathrm{c}} \mathrm{kg}^{-1}$ na condição de mata (RIBEIRO et al., 1999). Contudo, semelhante aos teores de sódio, não diferiu estatisticamente entre as áreas estudadas (gráfico 3). 
As plantas exigem grande quantidade de potássio, perdendo apenas para o nitrogênio. Este nutriente não faz parte de nenhum composto orgânico nas plantas, mas participa de vários processos essenciais para as plantas como a ativação enzimática, fotossíntese, regime hídrico das plantas, formação de aminoácidos e síntese de proteínas. Porém seu excesso pode aumentar sua taxa de absorção e interferir diretamente na absorção do cálcio e magnésio (MALAVOLTA, 1996c; MEURER, 2006). No caso estudado, pode estar havendo efeito antagônico na absorção de cálcio que se encontra em baixa concentração nos solos estudados (gráfico 2).

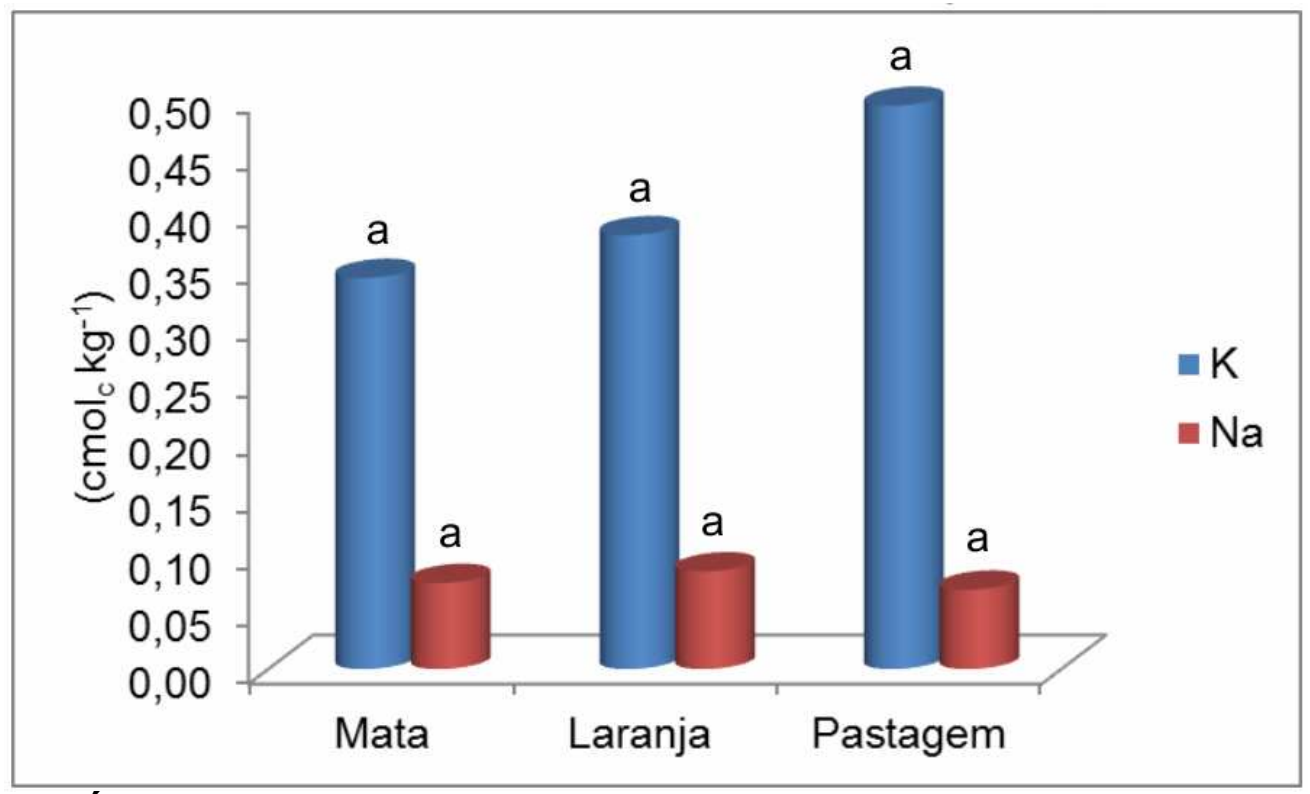

GRÁFICO 3. Teores de potássio e sódio nas três condições de uso do solo estudadas. Médias seguidas de mesma letra não diferem estatisticamente entre si pelo teste de Tukey ao nível de $5 \%$ de probabilidade.

Os teores de fósforo (gráfico 4) variaram de baixo nas condições de mata $\left(9,16 \mathrm{cmol}_{\mathrm{c}} \mathrm{kg}^{-1}\right)$ e laranja $\left(8,11 \mathrm{cmol}_{\mathrm{c}} \mathrm{kg}^{-1}\right)$ a muito baixo na condição de pastagem $\left(6,47 \mathrm{cmol}_{\mathrm{c}} \mathrm{kg}^{-1}\right)$ (RIBEIRO et al., 1999). Entretanto, não diferenciaram estatisticamente entre si. Este resultado é típico de solos de regiões tropicais, onde as argilas possuem grande capacidade de fixação do fósforo no solo, deixando-o indisponível às plantas.

O fósforo é um dos nutrientes que o agricultor deve dar muita atenção, buscando sempre corrigir as deficiências, pois o mesmo participa de vários processos metabólicos nas plantas, como a transferência de energia, síntese de proteínas, metabolismo de açúcares, armazenamento e transferência de energia, na divisão celular, no alongamento das células e na transferência da informação genética (MALAVOLTA, 1996d; ARAÚJO \& MACHADO, 2006). Este nutriente pode ser considerado um dos mais limitantes a produção agrícola brasileira, estando frequentemente em baixas concentrações nos solos brasileiros, principalmente em função do material de origem e de sua adsorção nas argilas, tornando-se indisponível às plantas. 


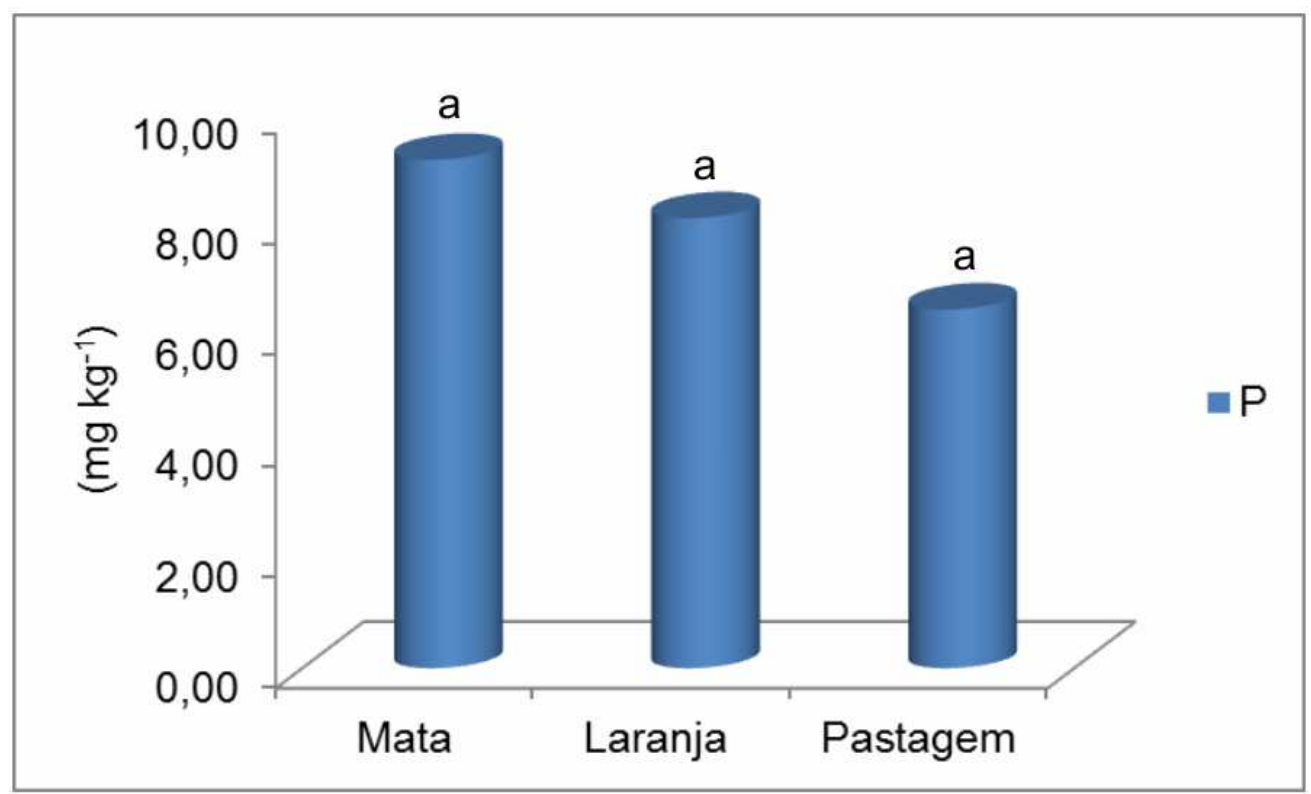

GRÁFICO 4. Teores de fósforo nas três condições de uso do solo estudadas. Médias seguidas de mesma letra não diferem estatisticamente entre si pelo teste de Tukey ao nível de $5 \%$ de probabilidade.

Os dados referentes aos teores de matéria orgânica (gráfico 5) das três condições de uso estudadas, mostram que a condição de cultivo com laranja possui maior teor de matéria orgânica $\left(3,16 \mathrm{dag} \mathrm{kg}^{-1}\right)$ no solo, seguido pela mata (2,66 dag $\mathrm{kg}^{-1}$ ) e pastagem $\left(2,49\right.$ dag kg $\left.{ }^{-1}\right)$, sendo todas as condições classificadas como de teor médio (RIBEIRO et al., 1999). Entretanto, a diferença no teor de matéria orgânica verificada no cultivo de laranja não foi suficiente para sua diferenciação estatística, não havendo diferença estatística entre as três condições de uso do solo estudadas.

A matéria orgânica do solo possui importante contribuição na fertilidade química e física do solo. Nos atributos físicos o teor de matéria orgânica no solo influencia o processo de agregação, estabilização de agregados no solo e como consequência a densidade e porosidade do solo. Nos atributos químicos, sua influência é principalmente devido a sua elevada área superficial específica e também a sua elevada densidade de cargas, influenciando a capacidade de troca de cátions (CTC) do solo, complexação de metais e seu efeito tampão do pH do solo, bem como, na disponibilização de nutrientes por sua mineralização (SILVA \& MENDONÇA, 2007). Neste sentido, se torna essencial elevar os teores de matéria orgânica dos solos estudados, por meio da aplicação de práticas conservacionistas. 


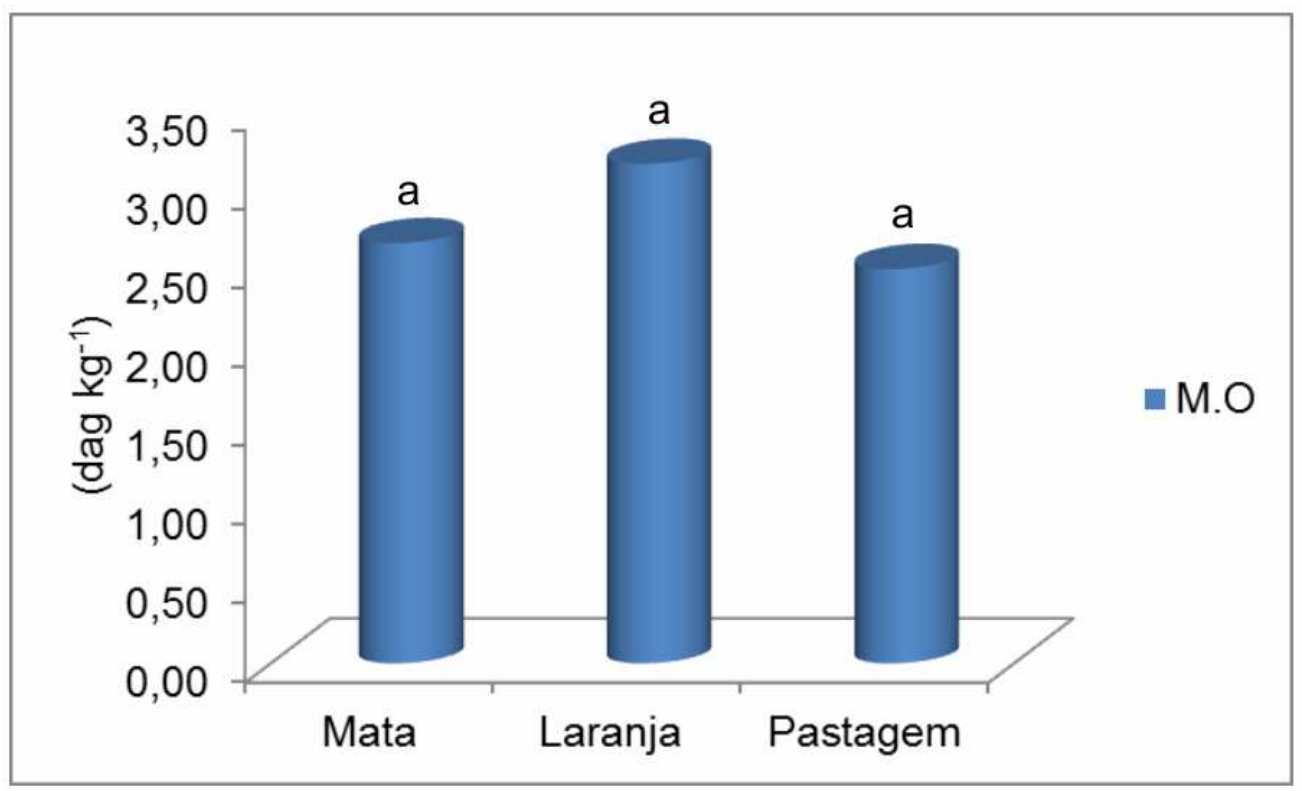

GRÁFICO 5. Teores de matéria orgânica nas três condições de uso do solo estudadas. Médias seguidas de mesma letra não diferem estatisticamente entre si pelo teste de Tukey ao nível de $5 \%$ de probabilidade.

O solo cultivado com laranja apresentou valores de CTC efetiva $\left(5,17 \mathrm{cmol}_{\mathrm{C}}\right.$ $\left.\mathrm{kg}^{-1}\right)$ e soma de bases $\left(3,18 \mathrm{cmol}_{\mathrm{c}} \mathrm{kg}^{-1}\right)$ considerados elevados conforme critérios de RIBEIRO et al. (1999) (gráfico 6). Na condição de mata e pastagem a CTC efetiva $\left(4,60\right.$ e 4,28 $\mathrm{cmol}_{\mathrm{c}} \mathrm{kg}^{-1}$, respectivamente) e soma de bases $\left(3,47\right.$ e 2,88 $\mathrm{cmol}_{\mathrm{c}} \mathrm{kg}^{-1}$, respectivamente) tiveram valores médios (RIBEIRO et al., 1999) (gráfico 6).

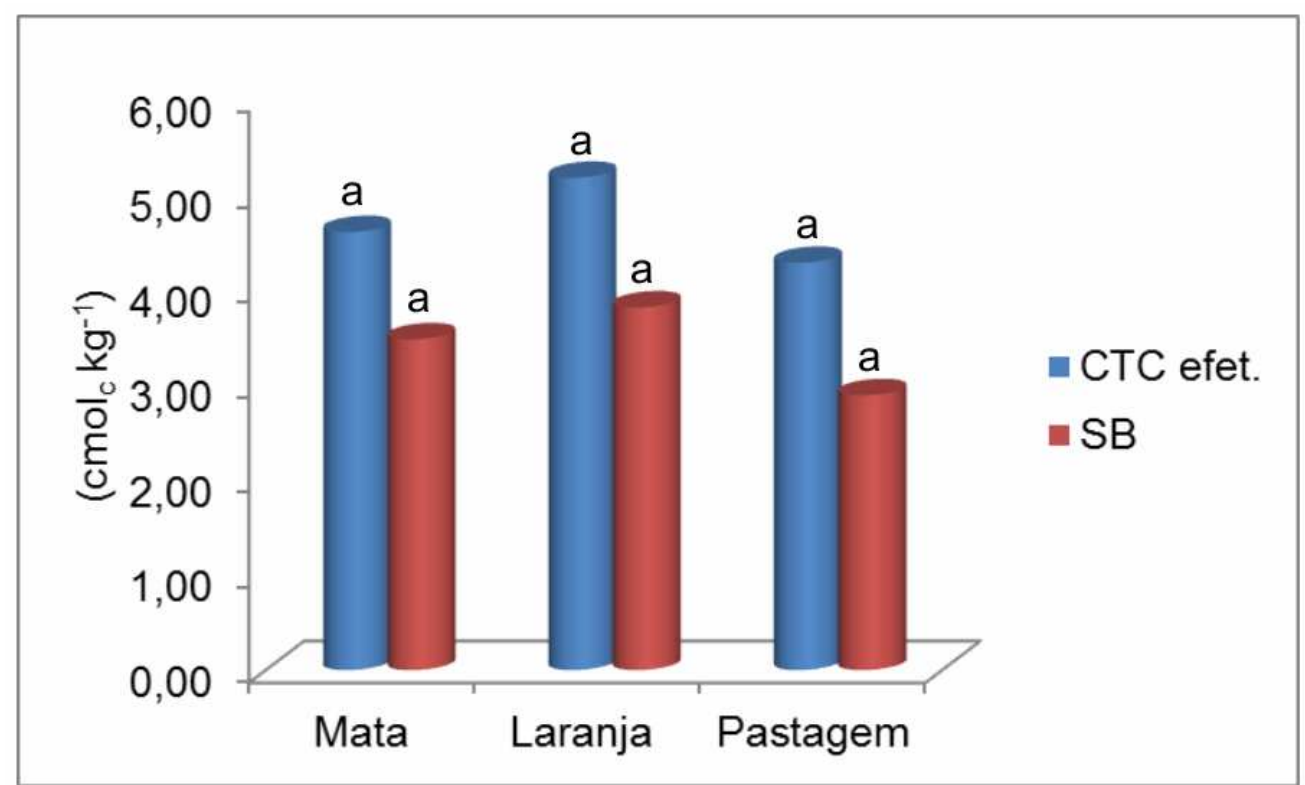

GRÁFICO 6. Valores da CTC efetiva e soma de bases nas três condições de uso do solo estudadas. Médias seguidas de mesma letra não diferem estatisticamente entre si pelo teste de Tukey ao nível de $5 \%$ de probabilidade. 
A saturação por bases é considerada baixa segundo RIBEIRO et al. (1999), em todas as condições estudadas (gráfico 7 ), variando de $21,11 \%$ no cultivo de laranja a $17,88 \%$ na pastagem e não diferiram estatisticamente entre si. Contudo a prática de calagem que será necessária para elevar $\mathrm{o} \mathrm{pH}$ do solo irá elevar a concentração de bases no solo, especialmente de cálcio que encontra-se em níveis baixos.

A saturação por alumínio (gráfico 7) é considerada baixa segundo RIBEIRO et al. (1999), para a condição de mata e laranja, porém média para a pastagem, mesmo não diferindo estatisticamente entre si. Necessitando de maior atenção principalmente na condição de pastagem que pode estar em processo de degradação, por um possível sobrepastejo.

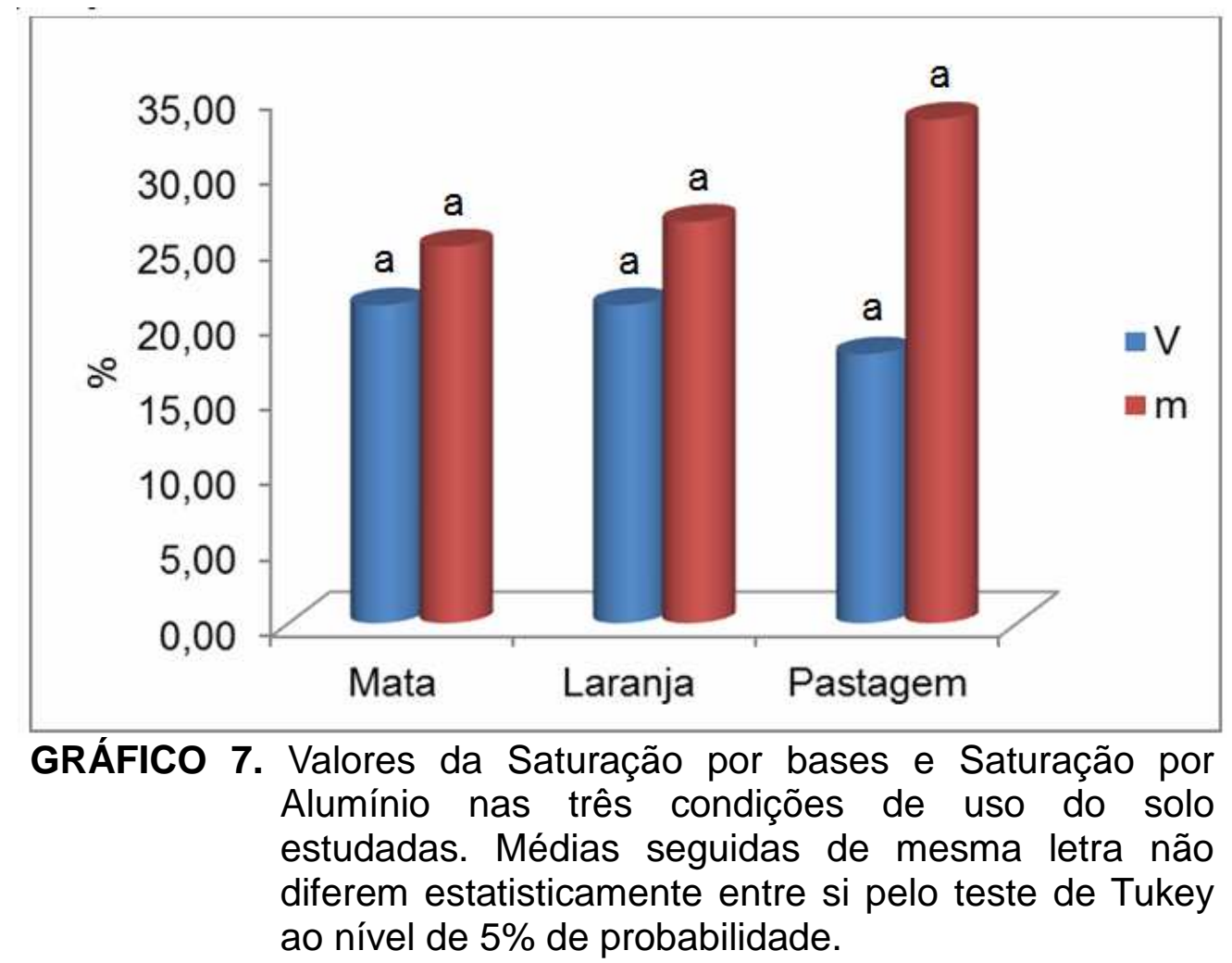

A densidade do solo e densidade da partícula foi estatisticamente semelhante para as distintas condições de uso dos solos estudados (gráfico 8). Havendo uma maior densidade do solo na condição de pastagem que reflete em menor porosidade total do solo e pode indicar certa degradação da pastagem estudada, devendo fazer uso de sistemas conservacionistas para tornar o sistema sustentável. 


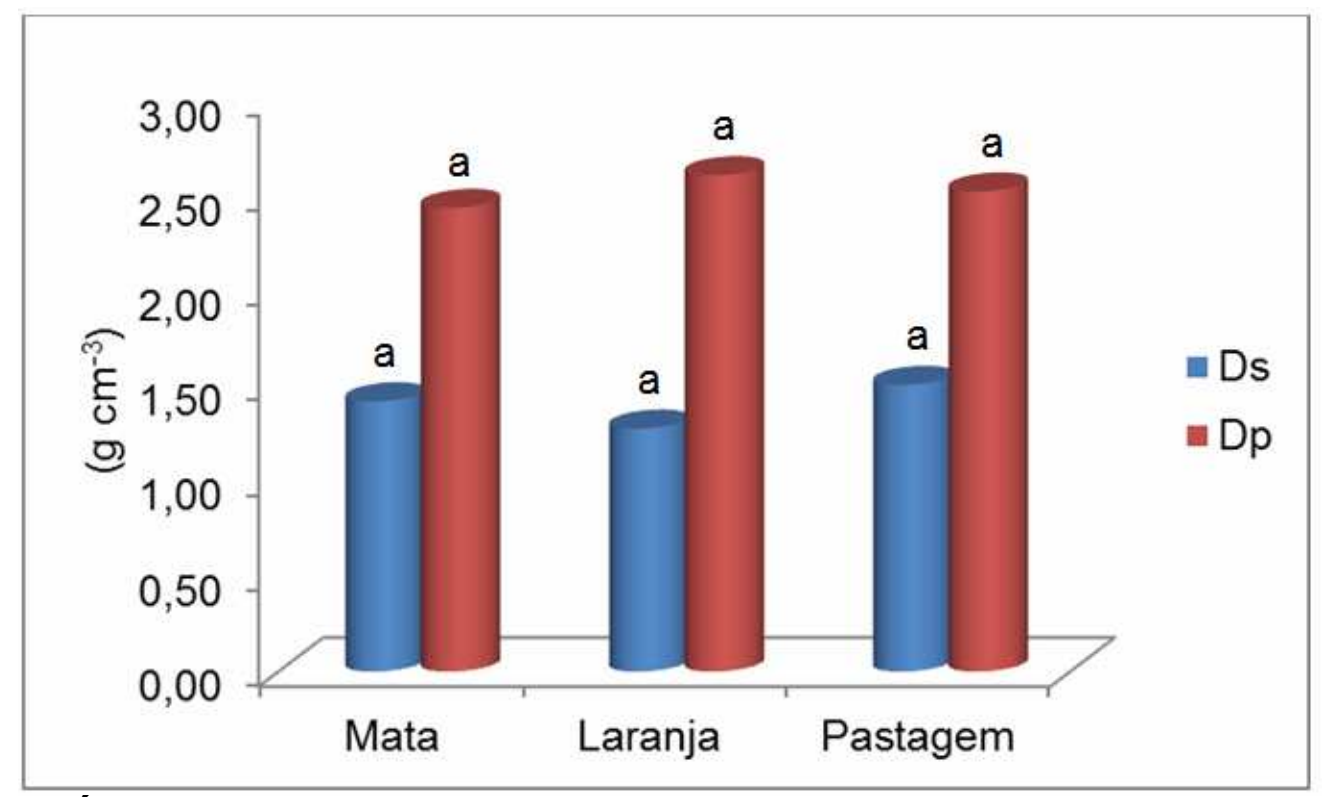

GRÁFICO 8. Valores da Densidade de partícula e densidade do solo nas três condições de uso do solo estudadas. Médias seguidas de mesma letra não diferem estatisticamente entre si pelo teste de Tukey ao nível de $5 \%$ de probabilidade.

A porosidade total do solo não diferenciou estatisticamente entre si (gráfico 9), porém observa-se uma tendência de compactação na condição de pastagem, que pode ser agravada se não houver um correto pastejo, evitando uma carga animal excessiva na área.

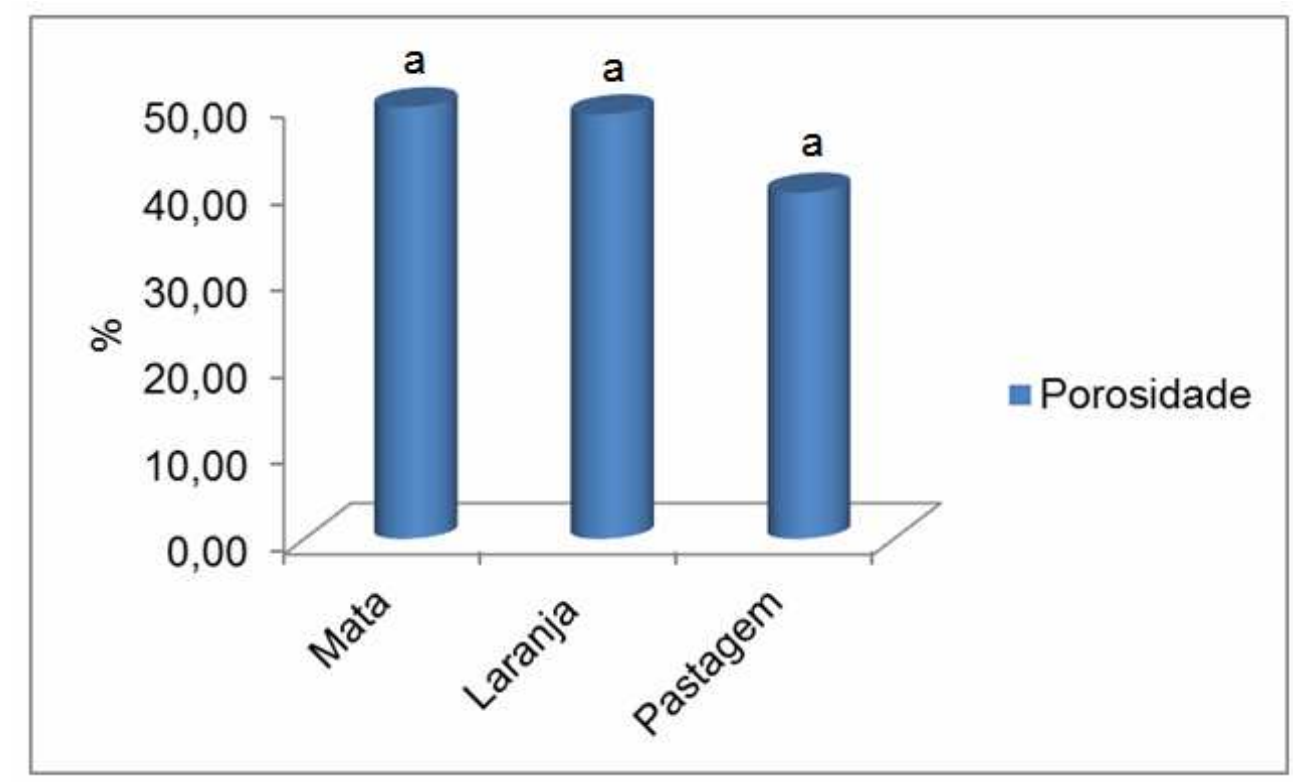

GRÁFICO 9. Valores da Porosidade nas três condições de uso do solo estudadas. Médias seguidas de mesma letra não diferem estatisticamente entre si pelo teste de Tukey ao nível de $5 \%$ de probabilidade.

O dendrograma de similaridade do gráfico 10, inicialmente possibilita observar 
a semelhança entre os atributos do solo nas áreas estudadas (laranja, pastagem e mata). Foram formados dois grupos distintos, um grupo com a área de laranja e outro grupo com pastagem e mata. Observa-se que as áreas de pastagem e mata são mais similares entre si, possivelmente como a pastagem possui mais de 20 anos de implantação já é uma condição mais estável que o cultivo de laranja que somente possui seis anos de implantação, estando em processo de estabilização de seus atributos químicos e físicos e por isso se encontra em um outro grupo de similaridade.

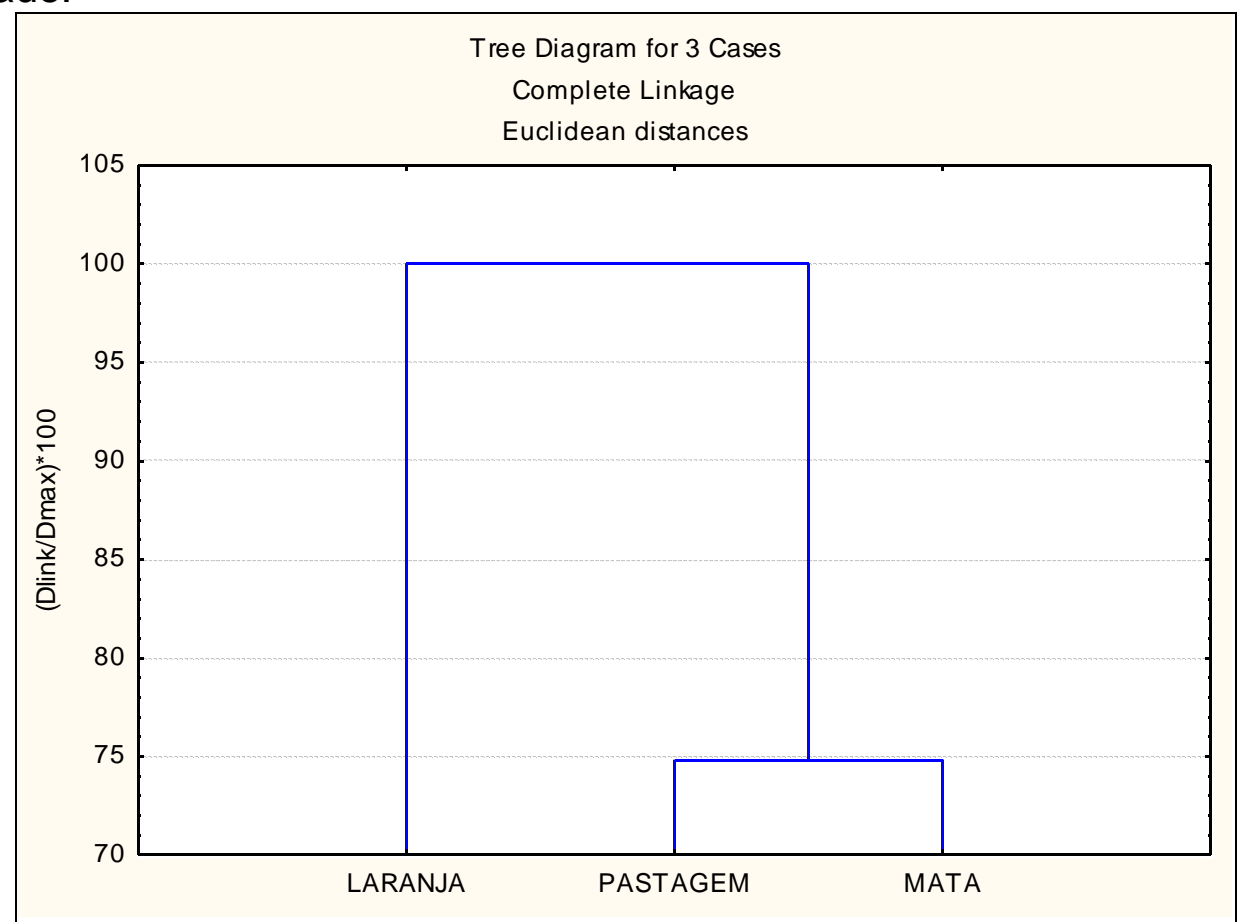

GRÁFICO 10. Dendrograma de similaridade com base nos atributos químicos ( $\mathrm{pH}$ água, $\mathrm{Ca}^{2+}, \mathrm{Mg}^{2+}, \mathrm{Na}^{+}, \mathrm{K}^{+}$, $\mathrm{Al}^{3+}, \mathrm{H}+\mathrm{Al}$, Valor S, m\%, CTCefet., CTCpot., CO e $\mathrm{P})$ e físicos (densidade de partícula, densidade do solo, porosidade total) dos solos estudados.

\section{CONCLUSÕES}

O uso do solo com pastagem, cultivo de laranja e mata nativa não diferiram estatisticamente entre si em todas as variáveis analisadas, possivelmente em função do pouco tempo de conversão da área de pastagem para cultivo de laranja.

O dendrograma de similaridade construído com as variáveis dos atributos químicos e físicos do solo mostra que a pastagem e mata nativa são mais semelhantes entre si, estando em grupo distinto do cultivo com laranja.

\section{REFERÊNCIAS}

ALVAREZ V., V. H.; NOVAIS, R. F.; BARROS, N. F.; CANTARUTTI, R. B.; LOPES, A. S. Interpretação dos resultados das análises de solos. In: RIBEIRO, A.C. GUIMARÃES, P. T. G.; ALVAREZ V., V. H. Recomendações para o uso de corretivos e fertilizantes em Minas Gerais - 5ª aproximação. Viçosa-MG, p. 23-32. 1999.

ARAÚJO, A.P.; MACHADO, C.T.T. Fósforo. In: FERNANDES, M.S. Nutrição Mineral 
de Plantas. Sociedade Brasileira de Ciência do Solo, Viçosa - MG, p. 254 - 273, 2006.

CAVALIERI, K. M. V.; CARVALHO, L. A.; SILVA, A. P.; LIBARDI, P. L.; TORMENA, C. A. Qualidade física de três solos sob colheita mecanizada de cana-de-açúcar. Revista Brasileira de Ciência do Solo [S.I.], v. 35, n. 5, p. 1541-1549, 2011.

COMPANHIA DE PESQUISA DE RECURSOS MINERAIS - CPRM. ServiçO Geológico do Brasil. Projeto cadastro de fontes de abastecimento por água subterrânea. Diagnóstico do Município de Santana do Mundaú, estado de Alagoas / Organizado [por] Mascarenhas, J. C.; Beltrão, B. A.; Souza Junior, L. C.; Galvão, M. J. T. G.; Pereira, S.N.; Miranda, J.L. F. Recife: CPRM/PRODEEM, 2005, $10 p$.

EMPRESA BRASILEIRA DE PESQUISA AGROPECUÁRIA - EMBRAPA. Manual de métodos de análises de solo. 2.ed. Rio de Janeiro, Ministério da Agricultura e do Abastecimento, 1997. 212p.

EMPRESA BRASILEIRA DE PESQUISA AGROPECUÁRIA - EMBRAPA. Mapa exploratório de reconhecimento de solos do município de Santana do Mundaú - AL. Embrapa Solos UEP Recife - PE, 2006. Disponível em: < http://www.uep.cnps.embrapa.br/solos/>, acessado em 27 de fevereiro de 2014.

HORST, W. J.; WANG, Y.; ETICHA, D. The role of the root apoplast in aluminiuminduced inhibition of root elongation and in aluminium resistance of plants: a review. Annals of Botany 106:p.185-197, 2010.

LEITE, E. M.; CAVALCANTE, L. F.; DINIZ, A. A.; SANTOS, R. V. D.; ALVES, G. D. S.; CAVALCANTE, I. H. L. Correção da Sodicidade de dois solos irrigados em resposta à Aplicação de Gesso agrícola. Irriga, Botucatu [S.I.], v. 12, n. 2, p. 168-176, 2007.

LOGAN, T. J., 1990. Chemical Degradation of Soil. Advances in Soil Science, v.11, p.187-221.

MALAVOLTA, E. É uma realidade - potássio é essencial para todas as culturas. Arquivo do Agrônomo № 10 (tradução). POTAFOS, Piracicaba - SP, 2p, 1996c.

MALAVOLTA, E. É uma regra (sem exceção) - o magnésio é exigido por todas as culturas. Arquivo do Agrônomo № 10 (tradução). POTAFOS, Piracicaba - SP, 2p, 1996b.

MALAVOLTA, E. Ele é essencial - sem fósforo as plantas não vivem. Arquivo do Agrônomo № 10 (tradução). POTAFOS, Piracicaba - SP, 2p, 1996d.

MALAVOLTA, E. Todo Mundo Sabe - o cálcio é exigido pelas culturas. Arquivo do Agrônomo № 10 (tradução). POTAFOS, Piracicaba - SP, 2p, $1996 a$.

MARASCA, I.; GONÇALVES, F. C.; MORAES, M. H.; BALLARIN, A. W.; GUERRA, S. P. S.; LANÇAS, K. P. Propriedades físicas de um Nitossolo Vermelho em função dos sistemas de uso e manejo. Rev. Bras. Eng. Agríc. ambient., v. 17, n. 11, p. 
1160-1166, 2013.

MEURER, E.J. Potássio. In: FERNANDES, M.S. Nutrição Mineral de Plantas. Sociedade Brasileira de Ciência do Solo, Viçosa - MG, p. 282 - 295, 2006.

MIELNICZUK, J. Matéria orgânica e a sustentabilidade de sistemas Agrícolas. SANTOS, G. A.; CAMARGO, F. A. O. In: Fundamentos da matéria orgânica do solo: ecossistemas tropicais e subtropicais. Gênesis, Porto Alegre, p 1 - 8. 1999.

REINERT, D.J. Recuperação de solos em sistemas agropastoris. In:Dias, L.E. \& MELLO, J.W.V., (Eds) Recuperação de áreas degradadas. Viçosa, Universidade Federal de Viçosa, Sociedade Brasileira de Recuperação de áreas degradadas, p. 162-176, 1998.

SILVA, I,R.; MENDONÇA, E.S. Matéria Orgânica do Solo. In: NOVAIS, R.F.; ALVAREZ V., V.H.; BARROS, N.F.; FONTES, R.L.F.F.; CANTARUTTI, R.B.; NEVES, J.C.L. (editores). Fertilidade do Solo. Sociedade Brasileira de Ciência do Solo, Viçosa-MG, p. 276 - 357, 2007.

SILVA, I. F.; MIELNICZUC, J. 1997. Avaliação do Estado de Agregação do Solo Afetado pelo Uso Agrícola. Revista Brasileira de Ciência do Solo, v.21, p. 313-319, 1997.

SOUSA, D.M.G.; MIRANDA, L.N.; OLIVEIRA, S.A. Acidez do solo e sua correção. In: IN: NOVAIS, R. F.; ALVAREZ V., V. H.; BARROS, N. F.; FONTES, R. L. F.; CANTARUTTI, R. B.; NEVES, J. C. L. (editores). Fertilidade do Solo. Sociedade Brasileira de Ciência do Solo, Viçosa-MG, 1르 ed. 275-374, p. 2007.

SOUZA, L. D.; RIBEIRO, L. S.; SOUZA, L. S.; LEDO, C. A. S. \& CUNHA SOBRINHO, A. P. Distribuição das raízes dos citros em função da profundidade da cova de plantio em Latossolo Amarelo dos Tabuleiros Costeiros. Revista Brasileira de Fruticultura, v. 28, n. 1, p. 87-91, 2006.

VITTI, G.C.; LIMA, E.; CICARONE, F. Cálcio, Magnésio e Enxofre. In: FERNANDES, M.S. (editor). Nutrição Mineral de Plantas. Sociedade Brasileira de Ciência do Solo, Viçosa - MG, p. 300 - 322, 2006.

VYSHPOLSKY, F.; QADIR, M.; KARIMOV, A.; MUKHAMEDJANOV, K.; BEKBAEV, U.; PARODA, R.; AW-HASSAN, A.; KARAJEH, F. Enhancing the productivity of highmagnesium soil and water resources in Central Asia through the application of phosphogypsum. Land Degradation \& Development [S.I.], v. 19, n. 1, p. 45-56, 2008. 